EESTI NSV TEADUSTE AKADEEMIA TOIMETISED 1954. III kd., nr. 4 ИЗВЕСТИЯ АКАДЕМИИ НАУК ЭСТОНСКОИ ССР 1954. ТОМ III. № 4

\title{
EBATSUUGA (DUGLAASIA) KASVATAMISE VÕIMALUSI EESTI NSV METSADES
}

\section{H. TAIMRE}

Eesti NSV metsade tootlikkuse tõstmine ja liigilise koosseisu täiendamine on üheks tähtsamaks metsamajanduse ülesandeks. Selle saavutamiseks tuleb suuremat tähelepanu pöörata uute, kiirekasvuliste ja tehniliselt väärtuslikku puitu produtseerivate puuliikide kultuuride rajamisele ning hinnaliste puuliikidega rajatud kultuuride ja puistute intensiivsemale hooldamisele. Kiirekasvuliste ja produktiivsete puuliikide viimiseks aladele, kus nad varem pole esinenud, on vajalik teostada põhjalikumaid vaatlusi ja uurimisi nende liikide kasvuomaduste tundmaõppimiseks. Kiirekasvuliste ja tehniliselt väärtuslike puuliikide sissetoomisel Eesti NSV metsadesse on seni omistatud suuremat tähelepanu lehisele ja paplile, mille kohta on kirjanduses avaldatud üksikasjalisemaid töid. Nagu Ukraina lääneosas teostatud uurimised on näidanud, osutub üheks hinnalisemaks ja kiiremakasvuliseks puuliigiks ebatsuuga. Samuti on andmeid aklimatiseerunud ebatsuuga kultuuride esinemise kohta Nõukogude Liidu Euroopa-osa kirderajoonides. Kirjanduses on mainitud ebatsuuga esinemist ka Eesti NSV parkides, aedades ja metsakultuurides. Millist ebatsuuga liiki on Eesti NSV-s kultiveeritud ja milliseid tulemusi siin on saavutatud, selle kohta puuduvad seni üksikasjalisemad andmed.

Eesti NSV-s esinevatest ebatsuuga kultuuridest tuleb esile tõsta Kaarepere metskonna Luua vahtkonnas rajatud ebatsuuga kultuure, mis väärivad tähelepanu oma hea kasvu tõttu. Ebatsuuga kasvab Luua vahtkonnas kolme eraldi puistuna, mille pindala on kokku 1,8 ha. Koosseisult on need puistud puhaspuistud, kus peale ebatsuuga esineb üksikute puudena ka kohalikke liike - kuuske ja valgeleppa. Peale selle on ebatsuugat istutatud gruppidena saare segapuistusse umbes 0,5 hektarisel pindalal (joon. 1).

Uuritavate ebatsuuga puistute kasvukoht Eesti NSV keskosas Jõgeva rajoonis Kurista metsamajandi Kaarepere metskonna Luua vahtkonnas kvartalitel nr. 135 ja nr. 139 kuulub oma muldade poolest jääkkarbonaatse mulla valdkonna kaguossa, kus pinnaehitust iseloomustab voorestiku esinemine. Siin esinevatele mullaerimitele on iseloomulik karbonaatne saviliiv ja liivsavi lähtekivim. Karbonaatne moreen lasub siin $60-100 \mathrm{~cm}$ sügavusel. Vaatlusaluste puistute kasvukoha mullad kuuluvad tugevasti leostunud kamar-karbonaatmuldade hulka, milledel on iseloomulik huumushorisondi aeglane üleminek järgnevaks horisondiks. Reljeefi iseloomustab siin lainjas tasandik veerja kallakuga lääne suunas. 


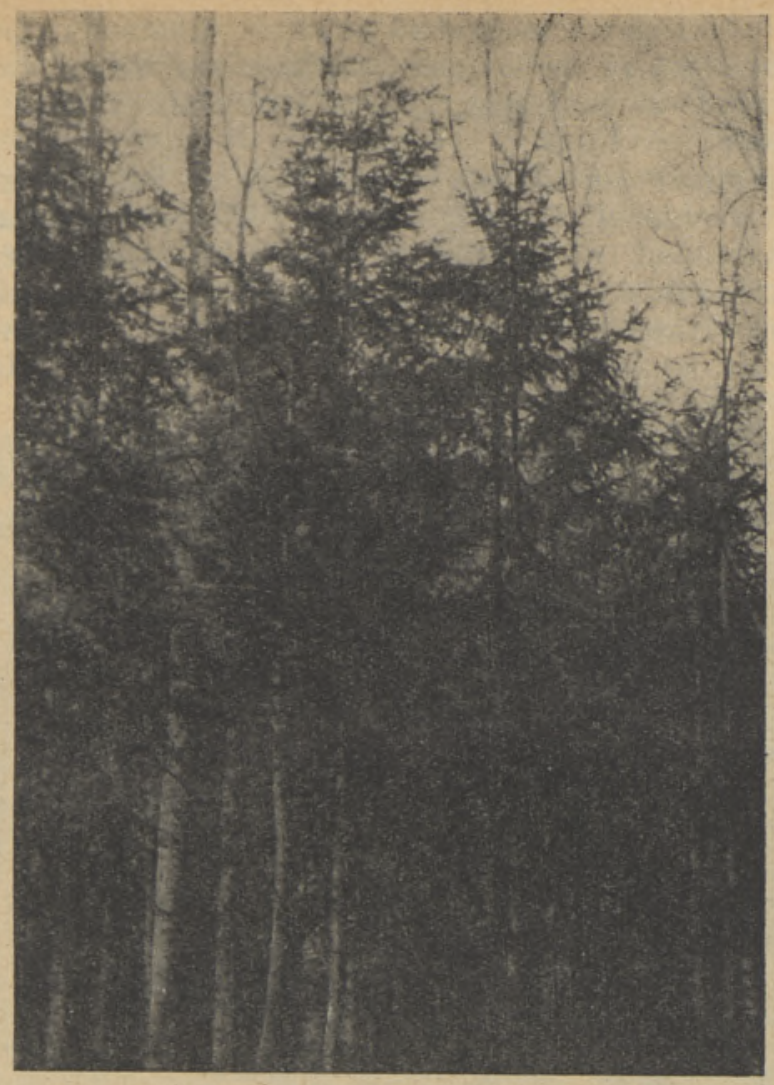

Joon. 1. Ebatsuuga grupid saare segapuistus Kaarepere metskonna Luua vahtkonna kvartalil 139.

Ebatsuuga kasvukohal saadi kaevamise teel järgmiste horisontidega mullaprofiil.

$A_{0} \quad 0-1 \mathrm{~cm}$ okka- ja oksapurust koosnev kõdu.

$\mathrm{A}_{1} \quad 1-30$, pruunikasmust huumuslik kerge liivsavi peenesōmeralise struktuuriga; hästi juurestunud, üleminek järgmisse horisonti aeglane; $\mathrm{pH} 6,8$.

AB 30-60 „, hallikaspruun jämeda struktuuriga keskmine liivsavi, milles leidub üksikuid 2-5-cm-se läbimõõduga lubjakivitükke; siia ulatuvad $A_{1}$-kihi huumuslikud sakid; juurestumine on nõrgemalt märgatav; keemine $55 \mathrm{~cm}$ sügavusel; $\mathrm{pH} 7,3$.

BC $60-80$ „ hallikaskollane karbonaatne raske liivsavi-moreen, sisaldab kuni 3-cm-se läbimõõduga lubjakivimunakaid ja paekruusa; siia tungib ka vihmaussi käike; pH 7,8.

C $\quad 80$, niiskem kollakashall kruusakas karbonatne savimoreen, milles esineb kuni 10-cm-se läbimōōduga lubjakivitükke; põhjavesi sügisel $1 \mathrm{~m}$ sügavusel.

Uuritava kasvukoha alustaimestik pole veel täielikult välja kujunenud, mis on tingitud puistu liiga tihedast liitusest enne hooldusraiete teostamist. Kuni 1950. aastani esines puistus ainult surnud pinnakate, 1953. a. suveks oli rohttaimestik hajusalt katnud uuritavat ala kolmandiku ulatuses. Taimkatte liigiline koosseis oli järgmine: jänesekapsas $\operatorname{cop}_{2}$, koldnõges $\operatorname{cop}_{1}$, sinilill sp., võ̃aülane sp., mitmeaastane seljarohi sp., metstarn sp., metspipar sp. Sammaldest esines ainult üks samblaliik - kähar salusammal (Eurynchium striatum), mis, kasvades rühmiti, kattis maapinda kümnen- 
diku ulatuses. Alusmets kasvukohal puudus. Ebatsuuga puistut ümbritsevate naaberpuistute ja nende kasvukohtade mullastiku vaatluste põhjal on kindlaks tehtud, et ebatsuuga puistu kasvukoht vastab salumetsatüübile $\left(^{1}\right)$. Boniteet on I-Ia.

Puistute rajamiseks on tolleaegse metsavahi A. Puhtzit'i andmetel kasutatud Kanadast pärinevat ebatsuuga seemet. (Katsed ebatsuuga kultiveerimise alal on näidanud, et Kanada päritoluga ebatsuuga seemned on osutunud Nõukogude Liidu põhjapoolsetel aladel kõige sobivamaks.) Seemnest kasvatati kohapeal kultiveerimiseks vajalikud taimed, millised 1916. aastal 3-4-aastaselt istutati- lageraielangile. Taimed on istutatud ridadena

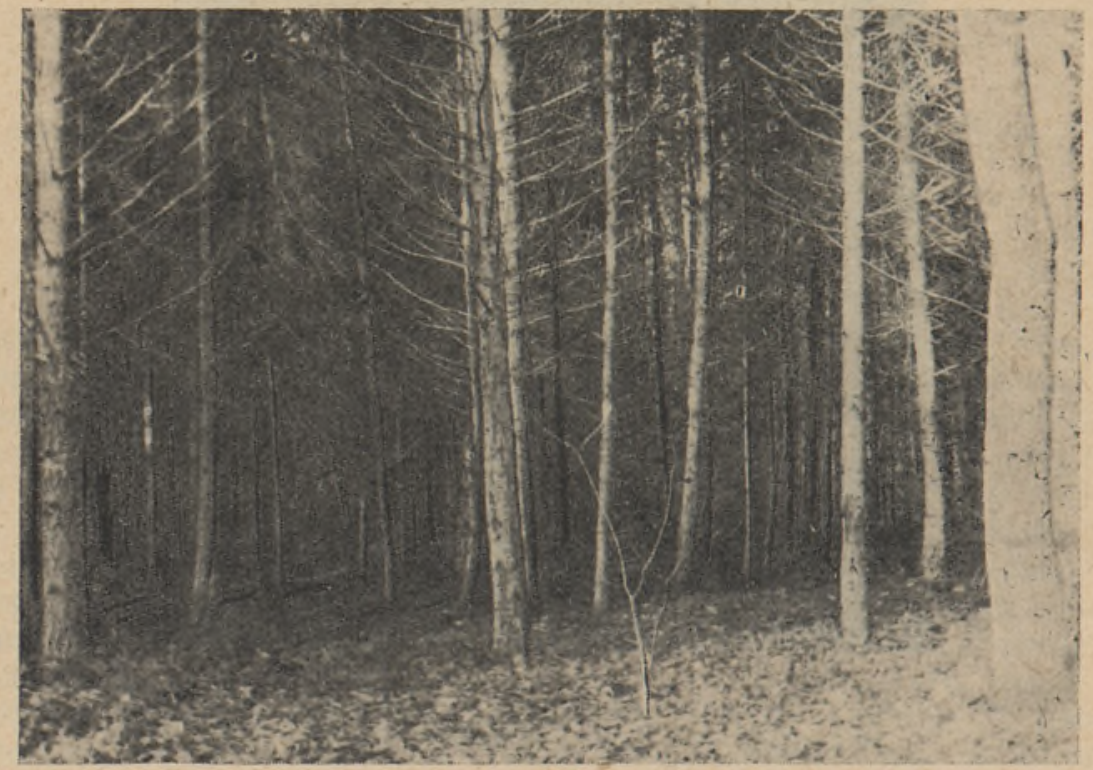

Joon. 2. Ebatsuuga kultuur kontroll-proovitükil nr. 3 Kaarepere metskonna Luua vahtkonna kvartalil 135 (vanus 38 a., keskmine kōrgus 17 m, keskmine diameeter $17 \mathrm{~cm}$, tagavara $310 \mathrm{tm}$ ha kohta).

seaduga $1,3 \times 1,4 \mathrm{~m}$, ca 5500 taime hektari kohta. Puistust seni saadud käbide järgi on kindlaks tehtud, et kultiveerimiseks on kasutatud peamiselt halli ebatsuuga (Pseudotsuga caesia) seemet, kuid puistus leidub rohkesti ka roheka ebatsuuga (Pseudotsuga taxifolia) seemnest kasvanud puid.

Jälgides puu-analüüsi andmeid ja puude kasvu looduses, nähtub, et Kaarepere metskonnas kultiveeritud ebatsuuga liigid kasvukiiruse suhtes ei jää maha meie kohalikest okaspuuliikidest - männist ja kuusest. Ainult lehis võib seniste andmete põhjal kasvukiiruses ebatsuugat ületada. Hoogsa kõrguskasvu tõttu ei ole ebatsuuga kultuuri ohustanud ei rohttaimede konkurents ega lehtpuude võsa. Kuna puistu hooldamisel pole puhastusraieid teostatud, on püsinud suur puude arv pinnaühiku kohta kuni puistu liitumiseni. Peale puistu liitumist, s. o. 20-25-aastaselt, on puude liigtiheduse tõttu puistus avaldanud mõju valgustingimuste halvenemine. Selle tulemusena vähenes puude suhteline võrapind, mis omakorda tunduvalt vähendas diameetri jooksvat juurdekasvu.

Ebatsuuga bioloogiliste omaduste uurimisel on selgunud, et valgusnõudlikkuse suhtes osutub ta männist varjusallivamaks, lähenedes ses suhtes kuusele. Seda tõendab puude eriti tihe liitus puistus ja suhteliselt pikk 
võra. Nii esines 35 -aastases ebatsuuga puistus ca 3000 puud hektaril ning niisuguse tiheduse tõttu alustaimestik puudus valguse vähesuse pärast. Usna hästi olid säilinud ka lehtpuude alla istutatud ebatsuuga grupid, kuigi nende kõrguse juurdekasv oli pidurdatud. Olulist tähtsust omab ebatsuuga kasvule valguse juurdepääs ülalt, kuid külgvarju talub ta hästi. Suurema varjusallivusega on ebatsuuga just nooremas eas, kuna vanemas eas tema nõuded valguse suhtes tunduvalt suurenevad.

Iseloomulik on Luua vahtkonna ebatsuuga puistutele eriti halb tüvede laasumine (joon. 2) vaatamata puistu tihedale liitusele. Samasugust pilti

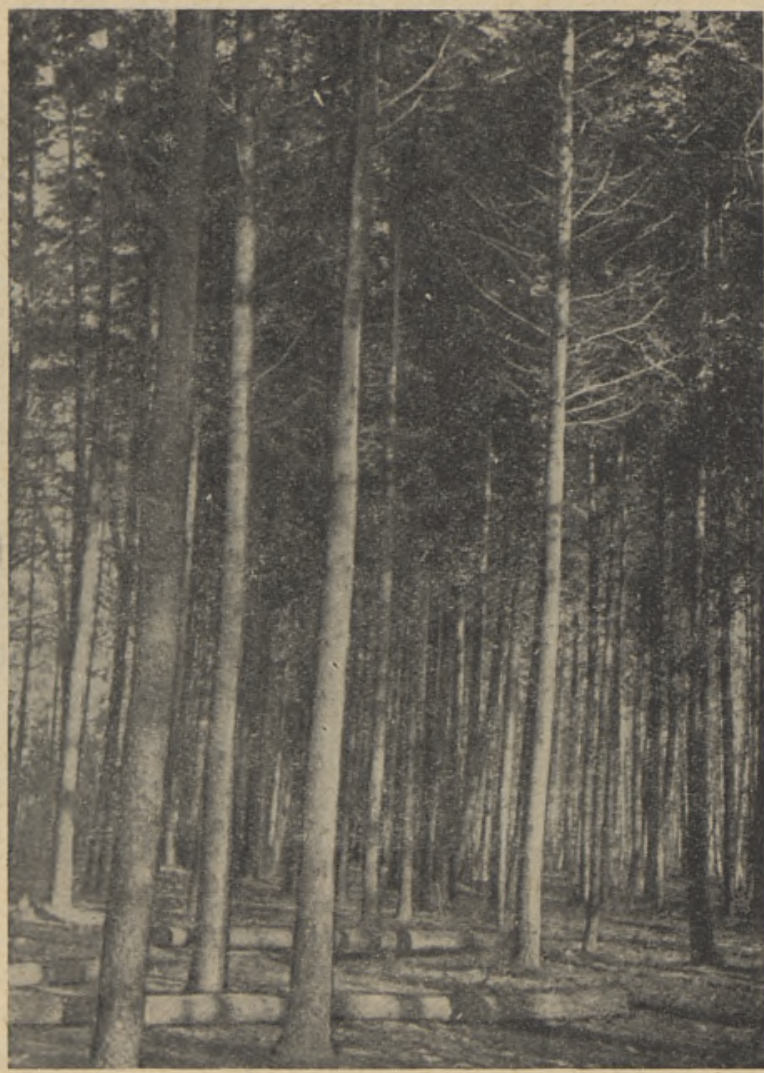

Joon. 3. Ebatsuuga kultuur proovitükil nr. 1 Kaarepere metskonna Luua vahtkonna kvartalil 135 pärast 1953. aastal teostatud mõõdukaastmelist hooldusraiet (vanus 40 a., keskmine kōrgus $18 \mathrm{~m}$, keskmine diameeter $18,2 \mathrm{~cm}$, tagavara $287 \mathrm{tm}$ ha kohta).

võib tüvede laasumises näha ka Purdi ja Sangaste metskonnas esinevates ebatsuuga kultuurides. Siinjuures tuleb märkida, et lehtpuudega segapuistus kasvavate ebatsuuga tüved on paremini laasunud kui puhaspuistus kasvanud puude tüved.

Omapäraseks nähtuseks Luua vahtkonna ebatsuuga puistutes on puutüvede alumise osa üsna tugev kõverdumine, mis eriti silma torkab alarinde puude juures. Ka mujal Eesti NSV-s esinevates ebatsuuga kultuurides, näiteks Purdi ja Sangaste metskonnas, võib näha ebatsuuga tüvede alumise osa kõverdumist. Selle nähtuse põhjustajaks on arvatavasti ebatsuuga juurekava ehitus ja tema tüvede paindeomadused, mistōttu ta allub kergesti 
tuule mõjudele ja lumevaalimisele. Juurekava vaatlused on näidanud, et ebatsuugal kujuneb tugevasti arenenud horisontaalne juurekava, kuid puudub tüüpiline sammasjuur.

Kaarepere metskonna Luua vahtkonnas kultiveeritud ebatsuuga liigid hall ebatsuuga ja rohekas ebatsuuga - on osutunud täiesti külmakindlaiks, nad talusid hästi ka 1939/40. a. talvekülmi. Rohekas ebatsuuga, mida meil kasvatatud ebatsuuga liikidest peetakse kõige külmatundlikumaks, on osutunud külmakindlaks arvatavasti tingituna sellest, et kultiveerimiseks on siin kasutatud roheka ebatsuuga loodusliku areaali põhjapoolsest osast (Briti Kolumbiast) pärinevat seemet; see on sobiv liik kasvatamiseks põhjapoolses kliimas.

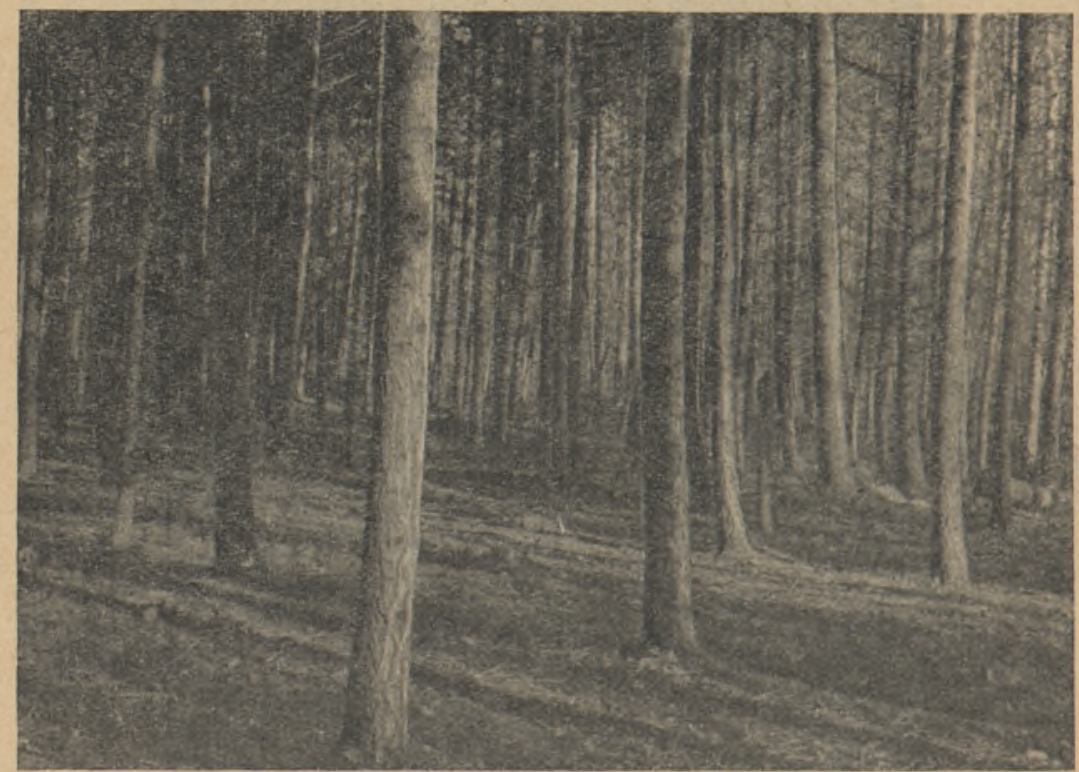

Joon. 4. Ebatsuuga kultuur proovitükil nr. 2 Kaarepere metskonna Luua vahtkonna kvartalil 135 pärast 1953. aastal teostatud tugevaastmelist hooldusraiet (vanus 40 aastat, keskmine kõrgus 18,6 m, keskmine diameeter $19,6 \mathrm{~cm}$, tagavara $254 \mathrm{tm}$ ha kohta).

Kaarepere metskonna Luua vahtkonnas esinevate ebatsuuga puistute tervislik seisund on hea. Seni pole märgatud seenhaiguste ja putukkahjurite esinemist. Seevastu Purdi metskonnas, kus ebatsuuga kultuur on rajatud 1921. aastal (pindala 2,0 ha) istutamise teel segus kuusega, võib üksikute alarinde ebatsuugade juures leida juurepessu (Fomes annosus) kahjustust. Samas puistus on aga kuusk juurepessust tunduvalt suuremal määral kahjustatud kui ebatsuuga. (Juurepessu levikut Purdi metskonnas on soodustanud mullastikulised tingimused - paas ja paerähk algab umbes $60 \mathrm{~cm}$ sügavuselt.)

Uuritava ebatsuuga puistu viljakandvuse algus oli 35 aasta vanuselt. Esimesed ebatsuuga käbid saadi puistu lõunapoolsel serval kasvavatelt puudelt. Kohapeal varutud ebatsuuga seemnete külvid on näidanud esialgu üsna nõrka idanemist $(10-20 \%)$.

Nii Kaarepere metskonna Luua vahtkonna kui ka Purdi metskonna ebatsuuga puistutes võib enamvalgustatud kohtadel ja metsa servadel leida üksikuid loodusliku külvi teel tekkinud taimi. Täiesti elujōulist ebatsuuga 
looduslikku uuendust leidub Kuusalu metskonna ebatsuuga puistutes (pindala ca $0,25 \mathrm{ha})$.

Et selgitada; millist mõju avaldavad hooldusraied ebatsuuga puistute arengule ja kuidas kulgeb puistus puude kasvukäik, selleks rajati Kaarepere metskonna Luua vahtkonnas ebatsuuga puistus 1950. aastal vastavad proovitükid. Kuni 1950. aastani oli nimetatud puistus hooldusraieid teostatud juhuslikult ja nõrgaastmeliselt. Selle tulemusena oli puistus säilinud ebanormaalselt suur puude arv, kusjuures kolmandik nendest asus alarindes. Hooldusraiete proovialad eraldati erineva tugevusega hooldusraiete teostamiseks. Proovitükil nr. 1 viidi läbi mõõdukaastmeline harvendusraie ja proovitükil nr. 2 - tugevaastmeline harvendusnaie (joon. nr. 3 ja 4). Peale selle eraldati veel kontroll-proovitükk nr. 3, kust võeti välja peamiselt surnud ja surevaid puid.

Proovitükid rajati 0,05 ha suurused, kuna suuremaid proovitükke ei lubanud rajada puistu iseloom ja litera kuju. Hooldusraieid proovitükkidel teostati vastavalt alameetodi põhimõttele. 1950. aastal teostati proovitükkidel esimene hooldusraie ja 1953. aasta suvel korrati samadel aladel hooldusraiet. Andmed hooldusraie tulemuste kohta on toodud tabelis 1 .

Tabel 1

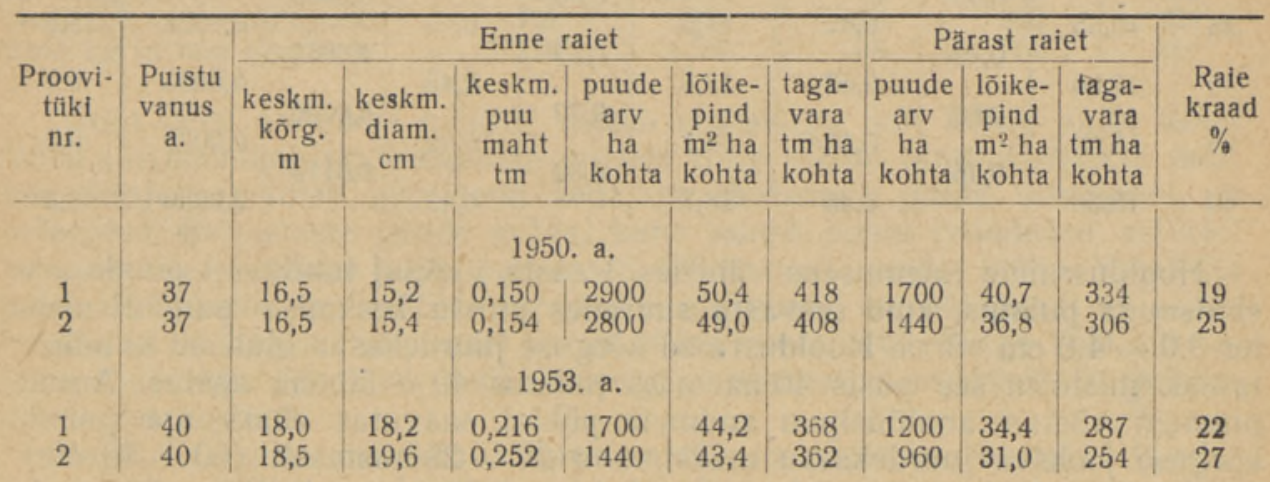

Andmed puistu tagavarade kohta arvutati välja keskmise mudelpuu meetodi järgi, kusjuures kummagi proovitüki juures kasutati kolme mudelpuu andmeid. Toodud andmeist nähtub, et efektiivse hooldamise puudumise tôttu on puistus säilinud erakordselt suur puude arv, sellega seoses on puistu tagavara suur, ületades tunduvalt standardtabelites samasuguse keskmise kõrgusega kuusepuistu kohta antud keskmised näitajad (tabel 2).

Tabel 2

\begin{tabular}{c|c|c|c}
\hline Puu liik & $\begin{array}{c}\text { Keskm. kõrgus } \\
\text { m }\end{array}$ & $\begin{array}{c}\text { Lõikepind } \\
\mathrm{m}^{2}\end{array}$ & $\begin{array}{c}\text { Tagavara } \\
\text { tm }\end{array}$ \\
\hline \multirow{3}{*}{ Kuusk } & 17 & 30,0 & \\
& 18 & 31,0 & 250 \\
& 19 & 32,0 & 272 \\
& & & 294
\end{tabular}

Tabelis esitatud arvud on puistu täiuse 1,0 juures.

Proovitükkide tagavarade võrdlemisel standardtabelite vastavate andmetega saame puistu täiuse peale teist hooldusraiet (1953. a.) 1,0 proovitükil nr. 1 ja 0,9 proovitükil nr. 2. Võrade liitust aga päraşt teist hooldusraiet võis proovitükil nr. 1 hinnata 0,8 ja proovitükil nr. $2-0,7$. Uuritavast puistust saadi pärast kaht hooldusraiet kolme aasta jooksul vahekasustusena proovitükilt nr. $1153 \mathrm{tm}$ ja proovitükilt nr. $2210 \mathrm{tm}$ puitu 
ha kohta. Uuritud ebatsuuga puistus ka varem teostatud väljaraiumiste tulemustega kokku ulatub 40-aastase puistu üldproduktsioon $450-530 \mathrm{tm}$ ha kohta.

Viie analüüsipuu andmete alusel saadi puistu kasvukäigu kohta järgmised keskmised andmed, mis on toodud tabelis 3 .

Tabel 3

\begin{tabular}{|c|c|c|c|c|c|c|c|c|c|}
\hline \multirow{2}{*}{$\begin{array}{c}\text { Puistu } \\
\text { vanus } \\
\text { a. }\end{array}$} & \multirow{2}{*}{$\begin{array}{c}\text { Puistu } \\
\text { keskm. } \\
\text { kõrgus } \\
\text { m }\end{array}$} & \multicolumn{2}{|c|}{$\begin{array}{c}\text { Kõrguse juurde- } \\
\text { kasv m }\end{array}$} & \multirow{2}{*}{$\begin{array}{c}\text { Puistu } \\
\text { keskm. } \\
\text { diam. } \\
\text { cm }\end{array}$} & \multicolumn{2}{|c|}{$\begin{array}{l}\text { Diameetri juurde- } \\
\text { kasv cm }\end{array}$} & \multicolumn{2}{|c|}{$\begin{array}{c}\text { Mahu juurde- } \\
\text { kasv tm }\end{array}$} & \multirow{2}{*}{$\begin{array}{c}\text { Mahu } \\
\text { juurde- } \\
\text { kasv } \\
\%\end{array}$} \\
\hline & & $\begin{array}{l}\text { jook- } \\
\text { sev }\end{array}$ & keskm. & & $\begin{array}{l}\text { jook- } \\
\text { sev }\end{array}$ & keskm. & $\begin{array}{l}\text { jook- } \\
\text { sev }\end{array}$ & keskm. & \\
\hline 5 & 0,15 & 0,03 & 0,03 & - & & & & & - \\
\hline 10 & 1,40 & 0,25 & 0,14 & 0,5 & 0,06 & 0,05 & 0,00003 & 0,00002 & - \\
\hline 15 & 4,00 & 0,65 & 0,27 & 4,5 & 0,82 & 0,30 & 0,0034 & 0,0003 & 34,9 \\
\hline 20 & 7,25 & 0,66 & 0,36 & 8,5 & 0.60 & 0,43 & 0,0064 & 0,0011 & 26,7 \\
\hline 25 & 10,55 & 0,49 & 0,42 & 11,5 & 0,39 & 0,43 & 0,0071 & 0,0021 & 15,3 \\
\hline 30 & 13,00 & 0,60 & 0,43 & 13,5 & $\begin{array}{l}0,09 \\
0,32\end{array}$ & 0,45 & 0,0096 & 0,0030 & 9,9 \\
\hline 35 & 16,00 & 0,46 & 0,46 & 15,1 & 0,32 & 0,42 & 0,0114 & 0,0039 & 9,0 \\
\hline 40 & 18,30 & & 0,46 & 16,7 & & 0,42 & & 0,0050 & 8,3 \\
\hline
\end{tabular}

Hooldusraiete tulemusena vähenes 3 aasta jooksul tunduvalt puude arv ebatsuuga puistus, kuid seevastu suurenes puistu keskmise puu diameeter $3,0-4,6 \mathrm{~cm}$ võrra. Hooldusraied kõrguse juurdekasvu oluliselt ei mõjutanud, mistõttu see püsis 40 -aastases puistus $40-50 \mathrm{~cm}$ aastas. Antud puistust võetud analüüsipuu andmete põhjal saavutas ebatsuuga puistu kõrguse jooksva juurdekasvu maksimumi $20-25$-aastaselt $(60-70 \mathrm{~cm})$ ja diameetri jooksva juurdekasvu maksimumi 20 -aastaselt $(70-80 \mathrm{~mm})$. Diameetri jooksvat juurdekasvu pole hooldusraied suutnud veel oluliselt muuta, 3 aastat on selleks osutunud liiga lühikeseks ajavahemikuks. Kuid võib märgata, et ka diameetri jooksva juurdekasvu langust ei esine.

Mahu juurdekasv 40 aasta vanuses ebatsuuga puistus oli 8,3 protsenti, mis ületab kasvukäigu tabelites toodud puistu juurdekasvu näitajad nii kuuse kui ka männi kohta.

Pärast hooldusraiete teostamist ilmnes ebatsuuga puistus puude tüvevormi tunduv paranemine tüve alumise osa kõverdumise suhtes. Puutüvede kvaliteedi tõstmise eesmärgil teostati ebatsuuga proovitükkidel pärast hooldusraiet kasvama jäänud puude laasimist.

Jälgides võrade liituse muutumist seoses hooldusraietega, võis tähele panna, et 3 aasta jooksul (s. o. pärast esimest hooldusraiet kuni teise hooldusraieni) toimus puistu võrakatuse peaaegu täielik liitumine. See fakt tõendab, et ebatsuuga reageeris antud juhul tugevaastmelistele hooldusraietele hästi, suurendades kiiresti võra pinda ja sellega seoses ka jämeduskasvu. Samuti näitab puude võrade head arengut asjaolu, et võrade pikkus moodustab hooldatud puistus vähemalt kolmandiku tüve üldpikkusest.

Ebatsuuga puidu füüsikalis-mehaaniliste omaduste kindlakstegemiseks langetati Kaarepere metskonna Luua vahtkonnas 5 mudelpuud, mis kuulusid erinevatesse kasvuklassidesse. Puidu füüsikalis-mehaaniliste omaduste määramist teostati 1954. aastal Tartus Eesti Põllumajanduse Akadeemia metsatakseerimise kateedri dotsent $\mathrm{K}$. Veermetsa poolt. Puidu omadused 
määrati 1,3 m tüve kõrguselt ja $1 / 2$ tüve kõrguselt vôetud katsekehade järgi. Ebatsuuga puidu omaduste üksikasjaline analüüs näitas, et paremate puidu omadustega olid II ja III kasvuklassi kuuluvad puud, kusjuures alarinde (IV kasvuklass) ja ülarinde, eriti tugevalt arenenud (I kasyuklass) puud olid nõrgemate puidu omadustega.

Tabelis 4 on esitatud keskmised andmed ebatsuuga puidu (niiskusesisaldusega 15\%) füüsikalis-mehaaniliste omaduste kohta. Võrdluseks on toodud puidu omaduste keskmised andmed kuuse kohta, mis on langetatud Kaarepere metskonna Luua vahtkonnas (I boniteet) ja männi kohta, mis on langetatud Eesti Pōllumajanduse Akadeemia õppe- ja katsemetsamajandis (I boniteet).

Tabel 4

\begin{tabular}{l|c|c|c|c|c}
\hline & $\begin{array}{c}\text { Puu } \\
\text { vanus a. }\end{array}$ & Mahukaal & $\begin{array}{c}\text { Surve- } \\
\text { tugevus } \\
\mathrm{kg} / \mathrm{cm}^{2}\end{array}$ & $\begin{array}{c}\text { Painde- } \\
\text { tugevus } \\
\mathrm{kg} / \mathrm{cm}^{2}\end{array}$ & $\begin{array}{c}\mathrm{Kõvadus} \\
\mathrm{kg} / \mathrm{cm}^{2}\end{array}$ \\
\hline Ebatsuuga 1,3 m tüve körguselt & 40 & 0,534 & 410 & 716 & 353 \\
Ebatsuuga 1/2 tüve kõrguselt & 40 & 0,491 & 376 & 579 & 320 \\
Ebatsuuga keskm. kokku & 40 & 0,517 & 396 & 669 & 339 \\
Kuusk 1,3 m tüve kõrguselt & 100 & 0,450 & 351 & 692 & 224 \\
Mănd 1,3 m tüve kõrguselt & 120 & 0,590 & 446 & 902 & 314
\end{tabular}

Nagu neist andmeist nähtub, ületab ebatsuuga puit kuuse puitu kõigi füüsikalis-mehaaniliste omaduste poolest ning männi puitu kõvaduse suhtes. Siinjuures tuleb arvestada seda, et ebatsuuga puidu omadused on määratud 40-aastaste puude kohta, kuna kuuse puidu omadused määrati 100 -aastaste ja männi puidu omadused 120 -aastaste puude kohta. Vastavad puidu füüsikalis-mehaaniliste omaduste uurimised on näidanud, et puidu omadused on vanematel puudel paremad kui noorematel. Seega võib arvata, et ka ebatsuuga vanemad puud on veelgi paremate puidu füüsikalis-mehaaniliste omadustega.

Nagu Kaarepere metskonna Luua vahtkonna puistutes teostatud tähelepanekud ja vaatlused näitavad, sobivad ebatsuuga kasvatamiseks värsked kuni niisked huumuselised liivsavimullad karbonaatsel savimoreen-aluspõhjal. Nendes tingimustes kasvab ebatsuuga hästi, ületades koguni meie kohalikke puuliike - mändi ja kuuske mitte ainult puidu toodangu, vaid ka puidu tehniliste omaduste poolest. Kuna kirjanduses $\left({ }^{2}\right)$ on mainitud, et ebatsuuga kasv jääb mõnel juhul meie kodumaa puude kasvust maha, siis võib see arvamus olla põhjustatud asjaolust, et kultiveerimiseks on valitud ebasobivaid kasvukohti ja puistute hooldamist pole teostatud korrapäraselt. Arvestades ebatsuuga looduslikku levikut oma kodumaal - mäestikes mitmesugustel kõrgustel, võib tema kasvatamine Eesti NSV oludes tulla kõne alla mitmesuguste kõrgendike nõlvakuil ja moreenseljandikel. Kuigi ebatsuuga oma looduslikul levikualal on mulla suhtes vähenõudlik, leppides leetunud muldadega ja kasvades ka kivistel pinnastel, tuleb meie oludes valida tema kasvukohaks viljakamaid pinnaseid. Kuna ebatsuuga juurekava on üsna pinnalähedane, siis pole soovitatav rajada tema kultuure ōhukestele ega ka liiga niisketele pinnastele, kus ta võib kannatada tormiheite ja lumevaalimise all. Tähelepanekud meil esinevate ebatsuuga puhasja segapuistute kohta lubavad järeldada, et ebatsuugat võib edukalt kultiveerida ka segapuistutena, näiteks salumetsa pinnastel. Meie oludes peaks katsetama ebatsuuga kultuuride rajamist võsastunud alade rekonstrueerimisel, sest ebatsuugat, eriti rohekat ebatsuugat, peetakse noores eas külma suhtes tundlikuks. Sellise kultiveerimisviisi juures pakub lehtpuu võra ebatsuuga noorendikele kaitset ja külgvarju. 
Arvestades ebatsuuga puistute suurt toodanguvõimet, puidu väärtust ning haiguse- ja külmakindlust, võib Eesti NSV oludes soovitada pöörata edaspidi suuremat tähelepanu ebatsuuga kultiveerimisele meie metsades.

Eesti NSV Pôllumajanduse Ministeeriumi
Kuremaa Metsakool
Saabus toimetusse 22. II 1954

\title{
KIRJANDUS
}

1. A. IIves, Eesti NSV arumetsatüübid, Loodusuurijate Seltsi juubelikoguteos, Tallinn, 1953, lk. 34.

2. A. V a ga ja K. Eichwa ld, Eesti NSV floora I, Tallinn, 1953, Ik. 142.

\section{О РАЗВЕДЕНИИ ЛЖЕТСУГИ (ДУГЛАСИИ) В ЛЕСАХ ЭСТОНСКОЙ ССР}

\author{
Х. Я. ТАИМРЕ
}

Резюме

При обогащении видового состава лесов Эстонской ССР новыми породами и при интродукции экзотов существенное значение имеет также выращивание лжетсуги. Культуры лжетсуги заложены во многих лесничествах республики. Наиболее значительные насаждения ее имеются в лесничествах Каарепере и Пурди. В последнем культура лжетсуги заложена в смеси с елью (на площади 2 га), а в лесничестве Каарепере - чистой породой (на площади 1,8 га). Возраст культур лжетсуги в настоящее время достигает $35-40$ лет.

Более обстоятельные исследования и наблюдения проведены автором в отношении культур, находящихся в обходе Лууа, лесничества Каарепере, у лесной школы Курема. Для закладки культур использованы главным образом семена лжетсуги серой (Pseudotsuga caesia), в меньшей мере лжетсуги зеленой (Pseudotsuga taxifolia), полученные из Канады. В лесничестве Каарепере культуры заложены трех-четырехлетними сеянцами в 1916 году. Культуры лжетсуги произрастают здесь на дерново-карбонатных выщелоченных суглинистых почвах на карбонатной морене. Бонитет $\mathrm{I}-\mathrm{I}$ a.

В отношении быстроты роста виды лжетсуги не уступают обыкновенной сосне и ели, только лиственница, по имеющимся данным, растет быстрее лжетсуги. Вполне хороший рост показывает лжетсуга в смеси с лиственными породами, как это видно на примере лжетсуг, посаженных пруппами в молодняк лиственных пород (рис. 1).

В исследованных насаждениях лжетсуги характерным является слабое очищение ствола от сучьев и значительная кривизна комлевой части ствола (рис. 2). Культивированные в лесничестве Каарепере виды лжетсуги оказались вполне морозостойкими, выдержав и сильные морозы в 1939/40 г. Санитарное состояние насаждений лжетсуги также вполне хорошее, только у единичных экземпляров угнетенного яруса в лесничестве Пурди замечены повреждения корневой губкой (Fomes annosus). Плодоношение лжетсуги в исследованных насаждениях началось в возрасте 35 лет. На опушках и на более освещенных участках леса обнаружены единичные всходы лжетсуги семенного происхождения. 
С целью выяснения влияния рубок ухода и для исследования хода роста в 1950 году в обходе Лууа, лесничества Каарепере были заложены соответствующие опытные площади насаждений лжетсуги. До 1950 года рубки ухода в исследуемых насаждениях носили случайный характер и проводились в слабой степени. Опытные площади закладывались для проведения рубок ухода различной степени и интенсивности (рис. 3 и 4). Первая рубка ухода на опытных участках была проведена в 1950 году и повторилась на этих же участках в 1953 году. Если принять во внимание и ранее проведенные рубки ухода на исследуемых участках, то общий запас древесины лжетсуги в 40-летнем возрасте достигает $450-530 \mathrm{~m}^{3}$ на га. Средний прирост по запасу равнялся $8,3 \%$. Проведение рубок ухода в насаждениях лжетсуги способствовало значительному улучшению формы стволов, уменьшению кривизны комлевой части ствола. С целью улучшения технических качеств ствола на опытных участках после проведения рубок ухода было произведено очищение ствола от сучьев.

Наблюдения, проведенные с целью выяснения влияния рубок ухода на развитие насаждений, показали, что лжетсуга реагировала хорошо на прореживание сильной степени, увеличивая быстро площадь кроны, в связи с чем увеличивался также и прирост по диаметру.

Для определения физико-механических свойств древесины лжетсуги было взято пять деревьев. Свойства древесины иоследовались доцентом кафедры лесной таксации Әстонской сельскохозяйственной академии К. Веэрметсом при 15-процентной влажности древесины. Исследованиями установлено, что по свойствам древесины лжетсуга значительно превосходит сосну и ель, особенно по твердости.

Как показывают наблюдения, в насаждениях лжетсуги в обходе Лууа, лесничества Каарепере, при климатических и почвенных условиях Эстонской ССР можно успешно выращивать культуру лжетсуги как в чистом виде, так и смешанными насаждениями. Разведение лжетсуги в лесах республики оправдывается ее значительной производительностью, высокими физико-механическими свойствами древесины и устойчивостью к морозам и заболеваниям.

Куремаская лесная икола Министерства сельского хозяйства ЭССР 